\title{
Cephalic Axial Skeletal-Neural Dysraphic Disorders: Embryology and Pathology
}

\author{
Miguel Marín-Padilla
}

\begin{abstract}
Three fundamental types of cephalic axial skeletal-neural dysrapic disorders are analyzed, including: cranioschisis aperta with encephaloschisis (anencephaly and/or exencephaly), cranioschisis occulta with occipital encephalocele, and the Chiari malformation (occipital bone hypoplasia) with compression, deformation and displacement of hindbrain, cerebellum, and medulla. Both clinical and experimental (vitamin A induced) examples of these malformations are used. The study establishes that these are not simple neurological (neural tube defects) disorders as it has been generally assumed, but complex developmental malformations affecting primarily the formation of the axial basicranium (causing skeletal defects) and the elevation of the neural folds and neurocranium (causing neural defects), and, secondarily, the topography of the facial skeleton or viscerocranium (causing oropharyngeal defects). The pathology of these skeletal, neural, and oropharyngeal defects is analyzed, their embryonic origin explored, and their developmental interrelationships discussed. The study proposes that an early paraxial mesodermal insufficiency may be the original anomaly common to all the different malformations that constitutes this heterogeneous group of dysraphic disorders. At any time during the segmental formation of the embryonic skeletal-neural axis, a simple reduction in the number of paraxial mesodermal cells produced by the Hensen node/primitive streak complex, could impair the formation of the axial skeleton as well as the elevation of the neural folds thus interfering with their closure. The final type of malformation is determined by variations of the degree, time of occurrence, and duration of the paraxial mesodermal insufficiency.
\end{abstract}

\begin{abstract}
RÉSUMÉ: Affections dysraphiques du squelette et du tissu nerveux axial de la tête. Nous analysons trois types fondamentaux de désordres impliquant un dysraphisme du squelette et du tissu nerveux axial de la tête dont: le cranioschisis aperta avec encéphaloschisis (anencéphalie et/ou exencéphalie), le cranioschisis occulta avec encéphalocèle occipital et la malformation de Chiari (hypoplasie de l'os occipital) avec compression, déformation et déplacement du rhombencéphale, du cervelet et du bulbe rachidien. Nous apportons des exemples cliniques et expérimentaux (induits par le vitamine A) de ces malformations. Cette étude démontre que ces affections ne sont pas de simples perturbations neurologiques (malformations du tube neural) comme on le pensait, mais des malformations congénitales complexes touchant principalement la formation axiale basicrânienne (causant des anomalies squelettiques) et l'élévation des crêtres neurales et du neurocranium (causant des malformations neurales) et, secondairement, la typgraphie du squelette facial ou viscérocranium (causant des malformations oropharyngées). Nous analysons la pathologie de ces anomalies squelettiques, neurales et oropharyngées, nous explorons leur origine embryonnaire et nous discutons de leurs interrelations au cours du développement. Cette étude propose que l'anomalie commune à l'origine de toutes ces malformations différentes constituant ce groupe hétérogène de désordres dysraphiques pourrait être une insuffisance mésodermique paraxiale précoce. Une simple réduction du nombre de cellules mésodermiques paraxiales produites par le complexe noeud de Hensen/ligne primitive survenant à n'importe quel moment pendant la segmentation de l'axe embryonnaire neuro-squelettique pourrait entraver la formation du squelette axial ainsi que l'élévation des crêtre neurales et interférer par le fait même avec leur fermeture. Le type final de malformation est déterminé par des variations dans le degré, le moment et la durée de l'insuffisance du mésoderme paraxial.
\end{abstract}

Can. J. Neurol. Sci. 1991; 18: 153-169

Axial skeletal-neural dysraphic disorders are complex and still poorly understood developmental malformations. In spite of an extensive literature, their nature and embryogenesis continue to be besieged by opposing points of view and misconceptions. 1-17 Those involving the cephalic as well as those involving the caudal region differ in the extent, severity, and location of the dysraphic defect. To describe each variation would be futile and would surely add unnecessary confusion to an already chaotic situation. Consequently, only three fundamental types of cephalic disorders will be analyzed here (Table 1). The objectives of this presentation are to describe their various pathologic anomalies, evaluate their developmental interrelationships, establish some foundations for understanding their embryogenesis, and, hopefully, clarify some of the confusion about their nature.

How can one justify another paper about these developmental malformations when the information already available

From the Professor of Pathology and Maternal \& Child Health, Department of Pathology, Dartmouth Medical School, Hanover, New Hampshire Reprint requests to: Dr. Miguel Marín-Padilla, Department of Pathology, Dartmouth Medical School, Hanover, New Hampshire, U.S.A. 03756 
about them is enormous? That information, in spite of its vastness, is incomplete, confusing, often one sided, and quite frustrating, as any student of these malformations would certify. That information has emphasized only the symptoms causing neurological defects (neural tube defects) while ignoring their axial skeletal and oropharyngeal anomalies. Perhaps this oversight alone is one of the main reasons for the persistent confusion about the embryogenesis of these disorders. ${ }^{11}$ It should be emphasized that without an adequate developmental pathologic assessment of their fundamental skeletal, neural, and oropharyngeal defects, it will be impossible to understand either their embryogenesis or their nature. The effects of the abnormal skull's base on the development of the nasal, buccal, pharyngeal, and laryngeal regions have not been fully appreciated in these disorders. Understanding these defects should be of value for neurosurgeons using an oral-pharyngeal approach for the posterior fossa decompression in the treatment of the Chiari malformation as well as for anesthesiologists using endotracheal intubation in affected infants. ${ }^{18-19} \mathrm{~A}$ better understanding of the nature of these disorders should also facilitate the pursuit of preventive measures as well as the exploration of new corrective therapeutic procedures.

\section{Materials And Methods}

Both clinical and experimental (vitamin A induced) examples of cephalic axial skeletal-neural dysraphic disorders from the author's collection have been used in this study. The selected cases from the human material (40 human skulls) include cranioschisis (unclosed cranium) aperta (CA) with encephaloschisis (anencephaly), cranioschisis occulta (CO) with encephalocele, and the Chiari malformation with hindbrain, cerebellum, and aqueduct developmental compression and deformation. Similar types of cephalic disorders have been selected from a large vitamin A induced experimental collection. Severe forms of each of these clinical and experimental malformations have been selected because they best demonstrate the characteristic defects. Each malformation is examined separately and, subsequently, all cases are comparatively analyzed. This study emphasizes: a) the similar involvement of the axial basicranium; b) the different involvement of the neurocranium and corresponding central nervous system; and, c) the less well-recognized secondary defects of the facial skeleton (viscerocranium) and subsequent anomalies of the nasal, buccal, pharyngeal, and laryngeal regions. To facilitate the description of these cephalic malformations, the embryology and anatomy of the human skull is briefly discussed.

\section{Embryology and Anatomy of The Human SkUld}

To adequately interpret any type of developmental malformation involving the cephalic region, it is essential to understand the embryology and anatomy of the skull's essential components. The term skull or cranium denotes the whole skeleton of the head and, consequently, includes the axial basicranium (skull base), the neurocranium (cranial vault), and the viscerocranium (facial skeleton). ${ }^{20-22}$ Each of these skeletal components evolves from a distinct source during a specific embryonic time and plays a different role in the organization of the nonskeletal cephalic components, including the central nervous system and the oropharynx. It should also be emphasized that each one of these skull components is differently affected in cephalic axial skeletal-neural dysraphic disorders. 23-27

By the time of birth, the human skull's articulations are either syndesmoses or synchondroses since none has yet become an ossified synostoses. This permits the dissection of each skull bone separately. The bones can subsequently be reassembled into whole crania (Figures 1, 2). Consequently, each normal or abnormal bone can be studied individually and compared with the corresponding bone from other normal or malformed skulls, and its articulations with other bones can also be assessed in reassembled skulls (Figures 1-3). This procedure facilitates the comparative study of normal and malformed disassembled or reassembled skulls (Figures 1-4). Although this procedure requires thorough and lengthy dissections, it is invaluable and unequaled for the study of the newborn normal or abnormal skull.

Midsagittal sections are preferable for the study of normal or abnormal cranial versus CNS relationships, as well as cranial relationships to nasal, buccal, pharyngeal, and/or laryngeal regions (Figures 5,6). Midsagittal sections are also valuable in assessing the position of the head, the length and angulation of the cranial base, the cranial base versus vertebral column angle, the pontine angle, the location of the tentorium, the size and shape of the subtentorial cerebral fossa, and the condition of the subtentorial CNS elements in normal and abnormal crania (Figures 5, 6).

The basicranium (axial chondrocranium) is the first axialskeletal anlage of the cranium and it is the oldest component. It is already established prior to the closure of the neural tube's anterior neuropore. An early concentration of paraxial mesodermal cells around the cephalic end of the notochord form parachordal plates from which the anterior region of the basicranium evolves. Recent investigations suggest that elements from tandem somitomeres (segmented mesoderm) might also participate in its formation. 28-30 The essential component of the basicranium's anterior region is the sphenoid bone, while the occipital

Figure I - Lateral, ventral, and frontal view's of the assembled skulls of a normal newborn $(\boldsymbol{A}, \boldsymbol{B}, \boldsymbol{C})$, and of an infant $(\boldsymbol{D}, \boldsymbol{E}, \boldsymbol{F})$ with anterior cranioschisis aperta and encephaloschisis/anencephaly are shown for comparative purposes and to evaluate their obvious developmental differences. The triangular shape, the extreme shortness of the skull's base, the transverse position and internal rotation of the temporal bones, the lack of a cranial cavity, the obvious defect in the neurocranium, (cranial vault), the relatively large and secondarily deformed facial skeleton, the narrow maxilla and mandible, and the overall lordosis of the malformed skull are illustrated. The abnormal skull is reproduced at slightly higher magnification than the normal one. These complex skeletal anomalies are not caused by the neural defect (encephaloschisis/anencephaly) but, they are the result of an early growth impairment (paraxial mesodermal insufficiency) that affects the formation of the skull base (basicranium anomalies), the elevation of the neural folds interfering with their closure (neurocranium and neural anomalies). as well as of secondary adaptations of the facial skeleton (viscerocranium anomalies). The arrows $(A, B, E)$ point to the tympanic ring which is visible in lateral view of the normal skull $(A)$ but is not in the malformed one $(D)$ due to the internal and anterior rotation of the temporal bones. Key: $p=$ parietal, $f=$ frontal, $o=$ basioccipital, $o$ $=$ lateral occipitalis, os-squama occipitalis, $t=$ temporal, $t s=$ squama temporalis, $z=$ zygomatic, $x=$ maxilla, $m=$ mandible, $s=$ sphe . noid, $p t=$ pterygoid process, and $n=$ nasal. The cervical vertebrae are numbered. 

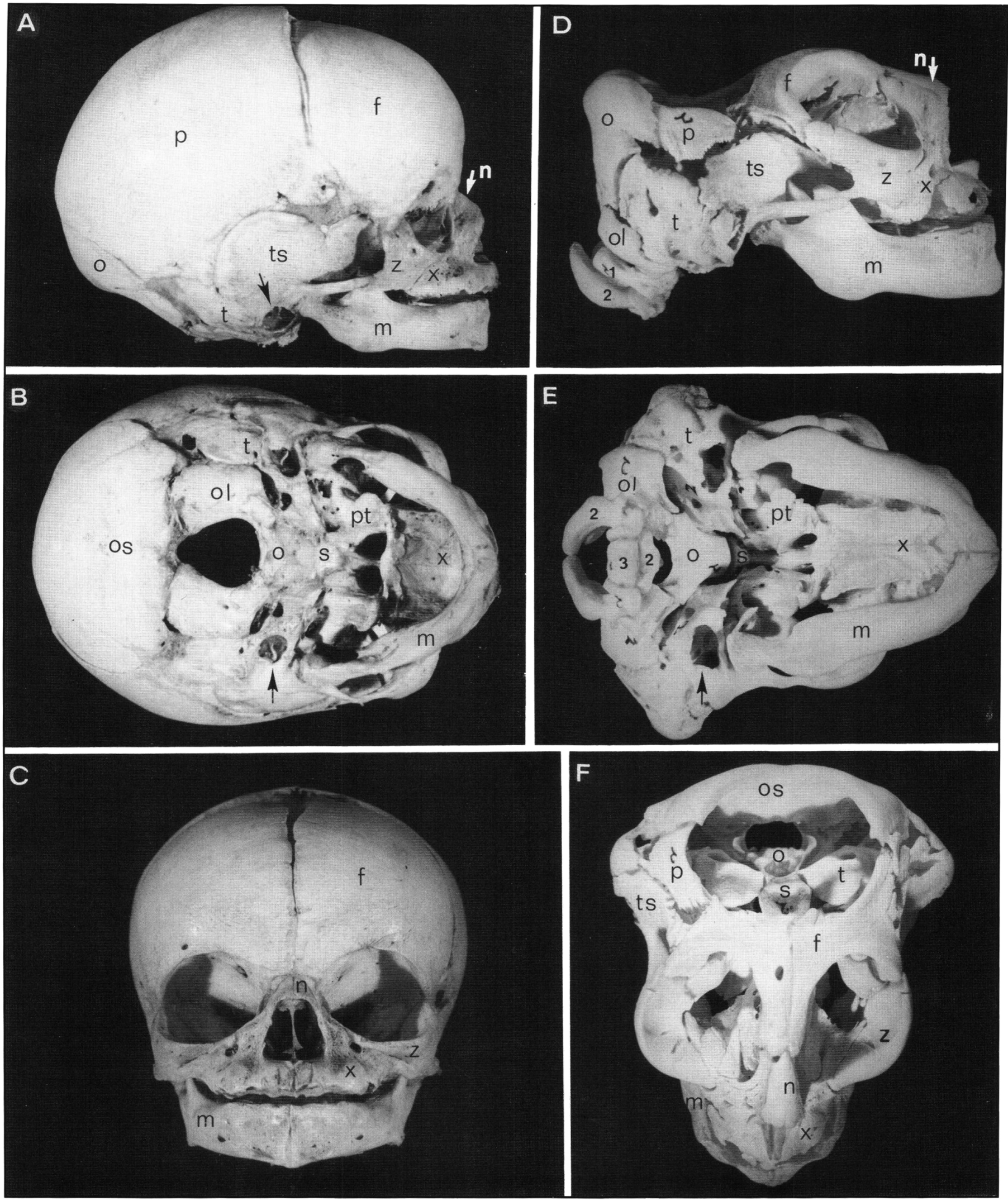

Figure I 
bone forms its posterior region. This bone evolves from the fusion of at least three occipital somites that subsequently become incorporated into the axial basicranium. Actually, the occipital bone behaves like a vertebra in human chondrodystrophies. ${ }^{31}$

The sphenoid (sphen + eidos $=$ wedge + resemblance $)$ bone is the central pivot of the skull. Because of its early development and central position, the sphenoid bone is closely related to the development of nearly all cephalic skeletal and non-skeletal components. Its early relationship to the olfactory, optic, and otic vesicles and, eventually, its articulation with their skeletal envelopes (ethmoid, frontals, and temporal bones) could determine their eventual location and orientation. Anteriorly, the sphenoid bone articulates with most of the facial skeleton (viscerocranium) components. Hence, it could indirectly determine the position and orientation of the nasal, buccal, pharyngeal, and laryngeal cavities. Posteriorly, it articulates with the occipital bone and could determine the location and orientation of the posterior cerebral fossa. Laterally, it articulates with the temporal bones and could also determine their position and orientation. Consequently, an early anomaly of the sphenoid bone could affect the subsequent development of practically every cranial bone and/or cephalic region.21,24

The paraxial unsegmented and, possibly segmented mesodermal origin of the essential components of the axial basicranium is an important developmental concept. A paraxial mesodermal insufficiency affecting the formation of the axial skeleton and the elevation of the neural folds could represent the common defect for the heterogeneous group of axial skeletal-neural dysraphic disorders. Such a defect supports the idea that cephalic and caudal dysraphic disorders are similar types of developmental malformations and explains their well-recognized clinical and familiar association.

The viscerocranium (facial skeleton) evolves from the cartilagenous centra (Meckel's, Reichter's pterygoid-quadrate cartilages) of the pharyngeal (branchial) aches, and it is primarily composed of migrating neuralcrest cells. The viscerocranium constitutes the skeletal support of the nasal, buccal and pharyngeal cavities. All of its essential bony components (mandible, maxilla, palatine, and zygomatic bones) articulate directly or indirectly to the sphenoid bone. In cephalic axial skeletal-neural dysraphic disorders, the bones of the viscerocranium are secondarily, rather than primarily, affected. Their anomalous position and/or rotation are secondary adaptations to a primarily abnormal axial basicranium. ${ }^{21,25}$

The neurocranium (cranial vault) protects and dorsally encloses the developing brain and is composed of various membranous bones. Early in embryonic development, the cephalic meninx primitiva evolves from paraxial unsegmented (prechordal and parachordal) and segmented mesoderm, and from neural crest cells. ${ }^{32}$ Later, the meninx primitiva splits into inner and outer components. The endomenin $x$ gives rise to the pialleptomeningeal brain envelope, and the ectomeninx forms the dura mater and an external layer of membranous mesoderm from which the bones of neurocranium evolve. The squamas of the frontal, temporal, and occipital bones, and the parietal bones are the neurocranium's essential components. In cephalic axial dysraphic disorders, the bones of the neurocranium are partially formed. The missing portion of these bones reflects the extent of the original defect in the closure of the cephalic neural folds and the corresponding defect in the dorsal ectomeninx (dura mater).

\section{Human Axial Skeletal-Neural DysRaphic Disorders}

Axial dysraphic disorders involving the cephalic region can be separated into at least three distinct groups that reflect different statuses in the closure of the neural folds (Table 1). A primary paraxial mesodermal insufficiency affects the formation of the axial basicranium and the elevation of the neural folds. If the developing neural folds do not reach the necessary elevation, they will not close normally. A failure of closure should affect the neural folds as a whole rather than the neuroectoderm (neural tube proper) alone, as has been erroneously proposed. 13,26,33-37 The severity of the paraxial mesodermal insufficiency determines the degree of failure in the closure of neural folds. In severe insufficiency, the neural folds fail to close altogether such that all components are affected (surface ectoderm, neural crest cells, supporting paraxial unsegmented and segmented mesoderm, and neuroectoderm). The neural folds might close partially, in moderate insufficiency, such that the surface ectoderm and its supporting mesoderm are able to close while the underlying neuroectoderm remains open. This kind of partial closure could explain disorders such as encephaloceles and meningomyeloceles. ${ }^{13,27,33}$ The neural folds could also close normally, as in the Chiari malformation. In any of these three situations, the axial basicranium should be similarly affected while the different involvement of the CNS should reflect the degree of failure in the closure of the neural folds (Table 1). Examples of cranioschisis aperta (CA) with encephaloschisis, cranioschisis occulta $(\mathrm{CO})$ with encephalocele, and the Chiari malformation (CM) with subtentorial CNS compression and deformation are analyzed separately here.

\section{Cranioschisis Aperta with Encephaloschisis (anencephaly)}

Partial or anterior (Figure 1D, E, F) and complete forms of cranioschisis aperta (Figure 3A, B, D) should be recognized (Table 1). The occipital bone, the posterior cerebral fossa and, hence, the subtentorial CNS structures are not involved in partial or anterior $\mathrm{CA}$ while they are involved in the complete forms (Figures 1,3). Partial $\mathrm{CA}$ is associated with encephaloschisis, and the unclosed and unprotected brain eventually degenerates (anencephaly). Complete CA is, in addition to encephaloschisis, characterized by occipital schisis with midbrain, hindbrain, and cerebellar involvement and eventual degeneration. In complete forms of $\mathrm{CA}$, the skeletal-neural axis may be totally, partially, or focally affected (Table 1). ${ }^{13.26}$ In these malformations, any unclosed region of the CNS lacking skeletal and/or meningeal protection eventually degenerates.

Figure 2-General view of all cranial bones of disassembled skulls from: $(\boldsymbol{A})$ normal newborn, and $(\boldsymbol{B})$ infant with cranioschisis aperta, occipital schisis and encephalocerebellar schisis for the comparative evaluation of their anatomical differences and to heighten the stunted sphenoid bone that characterizes these malformations. Only the sphenoid bone is primarily affected in cranioschisis aperta while most of the remaining bones are secondarily affected. The following bones, starting from the lower row, are illustrated: a) frontals, lacrimals, mandible, nasals, ethmoids, and turbinates; b) auditory ossicles, zygomatics and maxilla with palatines and vomer; c) temporals with squama and sphenoid; d) basi-occipital, and lateral occipitalis; and, e) parietals and the occipital squama with its planum nuchale and occipitalis. 


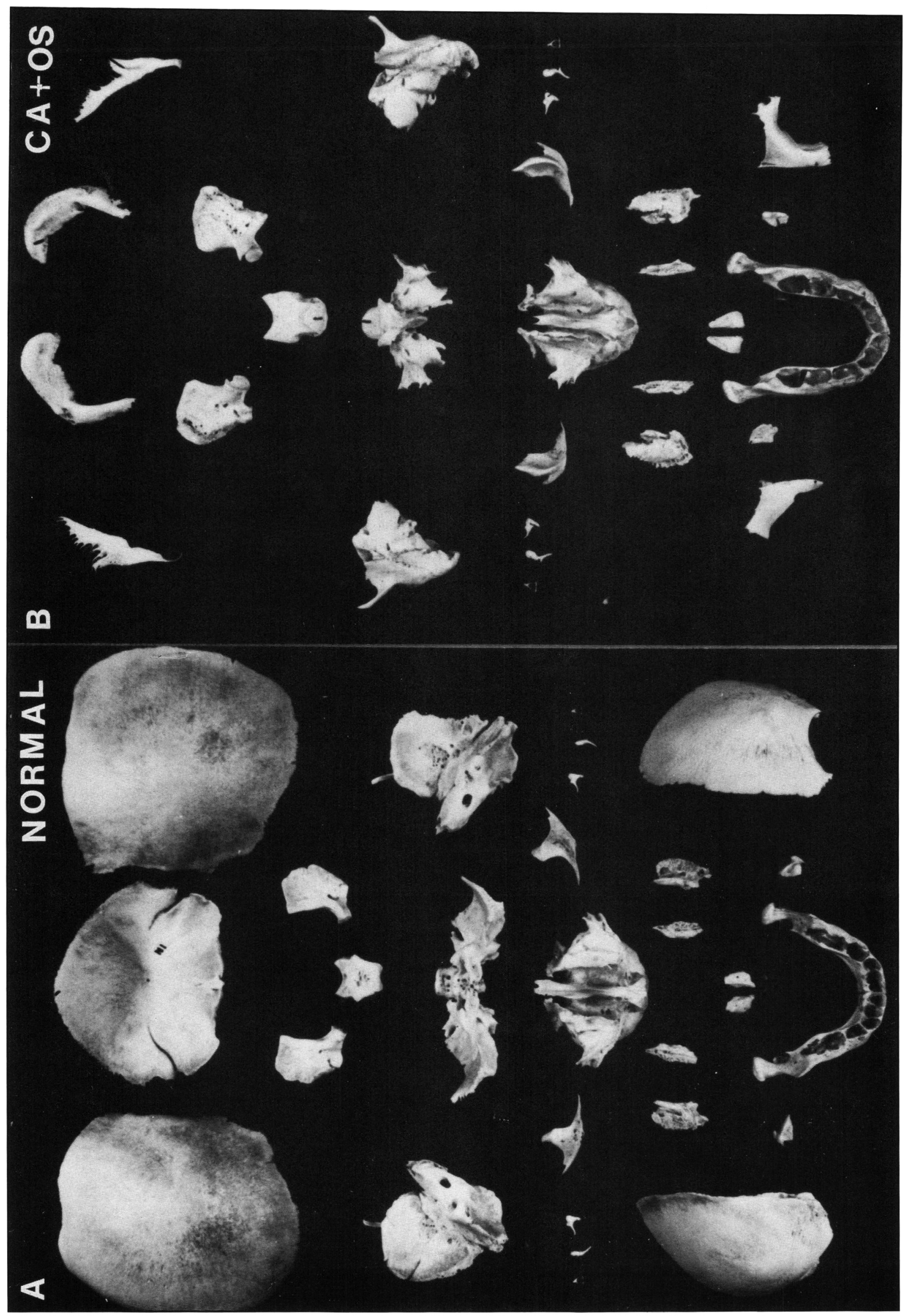


The skeletal, neural, and oropharyngeal defects that characterize these malformations will be analyzed separately here.

Skeletal Defects A simple comparison of the reassembled skulls of a normal newborn and of an infant with CA demonstrates obvious and remarkable differences (Figure 1). In CAs, the skull is quite abnormal, and its various anomalies cannot be explained simply as the result of CNS involvement as it has been proposed (Figure 1D, E, F). The persistent misconception that skeletal defects are secondary to neurological anomalies explains why there are so few basic anatomical studies of cranial malformations. ${ }^{21-27}$

The anatomical study of the reassembled skulls of partial CA (Figure 1D, E, F), complete CA with occipital schisis (Figure 3A, B), and CA with occipital and cervical schisis (Figure 3D) demonstrates features common to all malformations as well as minor variations that distinguish each one. The overall shape of these skulls is roughly triangular, rather than spheroidal (compare normal and abnormal skulls in Figures 1 and 3). Contrary to the opinion of some investigators, all the bony components of the cranium are present in these skulls. ${ }^{38-41}$ Although the degenerated intracranial portion of cranial nerves and main vessels are unrecognizable in encephaloshisis (anencephaly), all the normal nerve and vascular foramina are recognized in these malformed skulls. The presence of these foramina supports the idea that all cranial nerves and vessels are normally formed in these malformations and that lacking bony and/or meningeal protection, they eventually degenerate (anencephaly). Furthermore, the anatomy of the extracranial or somatic portion of these nerves (including the eyes) and of the principal vessels is unremarkable and recognizable in its entirety.

Neither of the abnormal skulls has developed a suitable intracranial space or cavity to accommodate the developing brain, which becomes extruded, and lacking bony or meningeal protection, degenerates. In partial (anterior) CA, a small posterior fossa may be formed that accommodates and prevents the degeneration of the cerebellum. In normal skulls, the space represented by the facial skeleton is proportionally quite small when compared with that of the whole cranium (Figure 1A, B). Contrarily, in CA skulls, the space represented by the facial skeleton is proportionally much larger than that of the cranium (Figure ID, E). This feature reflects the extreme shortness and lordosis of the skull base (Figures 5B, 6D). The short and lordotic skull base also explains the elevated position of the head, the short neck, and the large face that characterize these malformed infants (Figure 6D). In all forms of CA, the facial skeleton is narrow, posteriorly rotated, and protuberant rather than vertical. The frontal bones are always rotated posteriorly resting on the sphenoid bone, and no anterior cerebral fossae are recognizable. The shallow, externally rotated, and oblique orbits explain the characteristic prominent and superficially placed eyes (frog eyes) of these infants. The temporal bones are in a transverse rather than normal oblique position (Figure $3 \mathrm{C}$ ), and they are internally rotated (Figures IF, 2A, B). Their tympanic rings are internalized and anteriorly rotated which explains the characteristic low-set ears of these infants. No middle cerebral fossae are recognized. In CA, the cranial versus vertebral column's angle is more lordotic than normal. The short, narrow, and lordotic skull's base in all forms of CA is due to a primary growth-stunted sphenoid bone.
An interpretation of all of these complex skeletal anomalies is necessary to understand the malformed skulls that characterize these dysraphic disorders (Figures 1-3). That interpretation is greatly facilitated if the different anomalies are separated into those affecting the bones of the axial basicranium, the viscerocranium, and the neurocranium, respectively. Then it is easier to understand the type of defect that characterizes each group of bones and their developmental interrelationships, and it becomes possible to assess the nature of the whole abnormal skull. The comparative study of disassembled skulls of normal and affected infants is essential to further facilitate this individual bone analysis (Figure 3A, B).

The study of these disassembled skulls has demonstrated first of all that only the sphenoid bone seems to be primarily abnormal in these malformations (Figure 3A, B). Its growth is stunted. It is small, narrow, short, and anteriorly rotated bone with prominent pterygoidal processes (Figures 1-3).21,24 A normal sphenoid bone has been analogized to a "bat with expanded wings". In CA this bone rather resembles a "bat with folded wings". Furthermore, the study of this bone in all types of CA (e.g. CRT with anterior rachischisis and omphalocele, simple CRT, CA with occipital and cervical rachischisis, complete CA with occipital schisis, and partial CA) demonstrates that it is similarly affected in all malformations (Figure 4). ${ }^{24}$ This important observation gives further support to the idea that an early injury affecting the formation of the sphenoid bone could represent the fundamental anomaly common to all forms of this cephalic dysraphic malformation and that the severity and extent of the defect could explain their different types. ${ }^{13.25,26}$ Furthermore, a primarily abnormal sphenoid bone could, through its various articulations, practically explain all of the skeletal anomalies that characterize the malformed skull of these malformations. ${ }^{24,25}$

Figure 3-Composite figure showing: $(\boldsymbol{A})$ dorsal and $(\boldsymbol{B})$ ventral views of the assembled skull of an infant with cranioschisis aperta, occipital schisis and encephalo-cerebellar schisis; $(C)$ dorsal view of the assembled skull of a normal newborn; and. (D) posterior view of the assembled skull of an infant with cranioschisis aperta, occipital schisis and cervical rachischisis, to facilitate their comparative evaluation and illustrate the extent of their basic developmental malformations. The triangular shape, the involvement of the occipital bone $(A, B)$, and that of the cervical vertebral column $(D)$, the lack of a cranial cavity, the transverse position of the temporal bones and their internal rotation, the narrow mandible and maxilla. and the small and stunted sphenoid bone that characterize these malformations are clearly illustrated. The spheroidal shape of the normal skull $(\boldsymbol{C})$, its cranial cavity with the anterior, middles and posterior fossae, the oblique position of the temporal bones, and the normally formed sphenoid bone are shown for comparative analysis. Both parietal bones and the squama occipitalis have been removed from the normal skull to display the entire cranial base as well as the size and position of its various skeletal components. In the malformed skulls $(\boldsymbol{A}, \boldsymbol{B})$ the temporal bones are in a transverse position and internally rotated, the sphenoid bone is extremely short and narrow, the tympanic rings (arrow) are internalized and rotated anteriorly, the facial skeleton is narrow and protuberant, and their shape is roughly triangular. The malformed skull $(\boldsymbol{D})$ illustrates both the involvement of the occipital bone as well as that of the $I^{\text {st }}, 2^{\text {nd }}$, $3^{\text {rd }}, 4^{\text {th }}$, and $5^{\text {th }}$ cervical vertebrae (spina bifida). Key: $n=$ nasal, $f=$ frontal, $z=$ zygomatic, $p=$ parietal,$s=$ sphenoid, $s w=$ sphenoid greater wing, $p t=$ pterygoid process, $t=$ temporal, $t s=$ squama temporalis, $O=$ basi-occipital, $o l=$ lateral occipitalis, os $=$ squama occipitalis, $v=$ vertebral (neural) arches, $x=$ maxilla, and $m=$ mandible. The cervical vertebrae are numbered. 


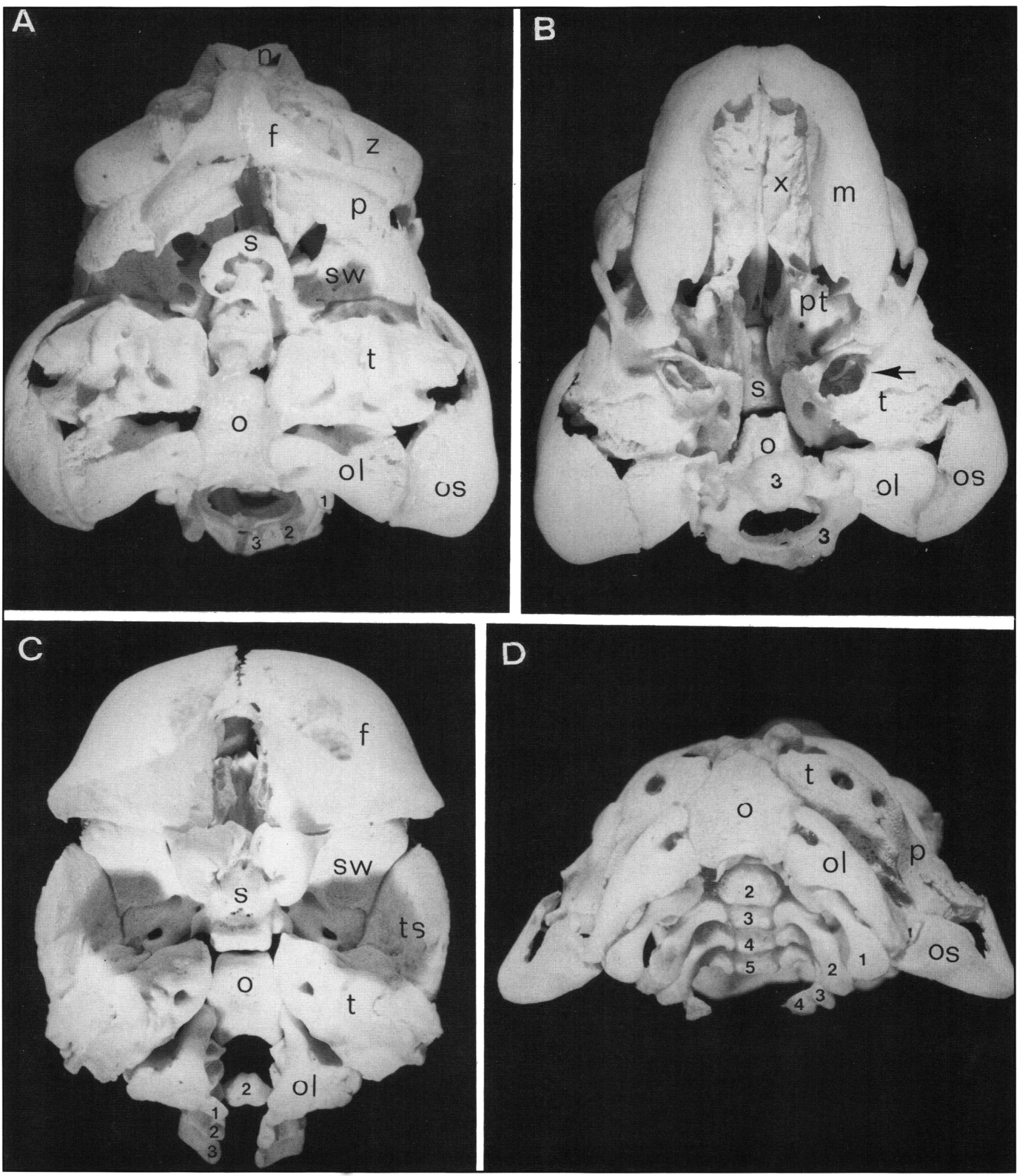

Figure 3 
The articulation of the sphenoid's large, closely set, and anteriorly rotated pterygoid processes explains all the anomalies of the facial (viscerocranium) skeleton. The prominent and protuberant face, the narrow and retroceded position of palatine and maxillary bones, the narrow nasal choanae, the small and narrow mouth, the short and narrow pharynx, and the anomalous position of the larynx are all secondary positional adaptations to a small sphenoid bone rather than primary defects. The closeness, transverse position, and internal rotation of the temporal bones also represent malpositions due to their articulation with a small, narrow, and anteriorly rotated sphenoid bone. The extreme shortness of the base of the skull is a direct consequence of a growth-stunted sphenoid bone. The lordosis of the base of the skull, the head elevation, and the short neck of the affected infants are similarly explained.

Consequently, it can be stated that the fundamental axial skeletal defect in all forms of CA is a growth-stunted, small, short, and anteriorly rotated sphenoid bone, and all remaining anomalies of the skull are in essence the result of secondary adaptations to this primarily abnormal bone. Also, the malformed skull in CAs is unsuitable to adequately accommodate the developing brain that extrudes and, unprotected, degenerates progressively (Table 1).

Neural Defects The cephalic CNS is obviously affected in all forms of $\mathrm{CA}$; it is unclosed (encephaloschisis). By the time of birth, it is impossible to assess the nature of the original brain defect because of its advanced degree of degeneration (anencephaly). It is indeed amazing how much has been written and how many theories have been based on an amorphous and meaningless mass (area cerebro-vasculosa) composed of fibrous, glial and vascular elements with an occasional neuron.

In the developing, but not yet degenerated, brain of the youngest fetuses with $\mathrm{CA}$, different cortical regions can be recognized. The cerebral cortex in such areas appears to be unremarkable, implying that both the ependymal neuronogenesis as well as the neuronal migration (which should be completed by the 16th-18th week of gestation) must have occurred normally in these infants. ${ }^{42}$ Although the encephalon is originally unclosed, the development of its different cortical structures seems to progress normally until secondary degeneration destroys them. Furthermore, the eyes with totally degenerated optic nerves and chiasm remain unaffected. Similarly, all cranial and spinal nerves with degenerated proximal portions remain distally unaffected in these infants. These findings support the idea that the neuroectoderm is not primarily but secondarily affected in these disorders.

The best explanation for the neural defects observed in any form of $\mathrm{CA}$ is that any region of the developing brain extruded for lack of a suitable cranial space and left unprotected without skeletal or meningeal envelopes eventually degenerates. Consequently, the progressive degeneration of the nervous tissue observed in these dysraphic disorders is a secondary phenomenon caused simply by exposure to trauma and the amniotic fluid. However, this interpretation only explains half of the problem; it does not explain why the neural folds fail to close in the first place. It should be emphasized that the paraxial mesoderm fills and supports the neural folds during their progressive formation/elevation, essentially acting like bilateral buttresses necessary for their closure. A failure of the neural folds to achieve the and necessary elevation because of a primary paraxial mesodermal insufficiency would certainly interfere with their closure. $1,2,8,10,12,13,23-27,33-37$ A severe insufficiency would cause a complete failure of closure (encephaloschisis), while a moderate one might allow the closure of the surface ectoderm and supporting mesoderm, leaving unclosed the neuroectoderm or neural tube proper (encephalocele and/or meningomyelocele). If the mesodermal insufficiency is minimal, the neural folds might be able to close normally, but the underlying axial skeleton should be affected as in the Chiari malformation (Table 1).

Oropharyngeal Defects In all forms of CA, the short, narrow, and lordotic base of the skull causes developmental deformations in the facial skeleton (viscerocranium) that result in characteristic and poorly recognized oropharyngeal anomalies. In affected infants, the oropharyngeal axis is lordotic, the buccal and pharyngeal cavities are short and narrow, the nasal choanae are narrow, the palate is compressed, and the tongue protrudes anteriorly (Figures 5B,6D). The typical protruding tongue of these infants caused by the small and short mouth has been erroneously interpreted as macroglossia. These visceral defects are deformations rather than malformations and represent secondary adaptations to the primarily abnormal skull's base.

In addition, the position and location of the larynx is also abnormal in CA (Figures 5B, 6D). The position of the larynx in $\mathrm{CA}$ is oblique rather than vertical (Figure 5D, E). Although the location of the larynx varies in the course of development, by the time of birth, the level of the epiglottis should be at about the odontoid process of the second vertebra below the atlas (Figure 5E). In CA, the level of the epiglottis is at about the third vertebra (Figure 5D, black/white arrow). The anomalous position of the larynx in CA is caused by the extreme shortness of the base of the skull, which seems to pull the vertebral column upward. Consequently, the anomalous position of the larynx in these disorders is another sequela of the primarily abnormal axial basicranium.

\section{Cranioschisis Occulta with Encephalocele}

The nature and embryogenesis of cranioschisis occulta ( $\mathrm{CO})$ with encephalocele have remained controversial in spite of the vast amount of information about these malformations. $6,7,9,14,25,27,36$ Although there are probably different types of developmental cephalic encephaloceles, some of them represent

Figure 4 - Anterosuperior view of the sphenoid bones of $(A)$ normal newborn and of various infants with: $(B)$ anterior cranioschisis aperta; (C) cranioschisis aperta and occipital schisis; (D) cranioschisis aperta, occipital schisis and cervical rachischisis; $(\boldsymbol{E})$ craniorachischisis totalis; and, $(\boldsymbol{F})$ craniorachischisis totalis with anterior dorsal rachischisis for a comparative evaluation, and to emphasize the nearly identical type of abnormality (stunted growth) of the sphenoid bone that characterizes all of these different axial skeletal-neural dysraphic disorders. The similarity of the basic sphenoid bone's abnormality, that characterizes all of these dysraphic disorders, supports the idea of a common paraxial mesodermal defect that affect equally the early formation of axial basicranium in all of them. The sphenoid bone in these disorders has been analogized to "a bat with close wings". The abnormal sphenoid bones are reproduced at a slightly higher magnification than the normal one. Key: $A=$ sphenoid bone's body, $B=$ lesser wings, $C=$ greater wings, $D=$ pterygoid processes, and $E=$ rostrum. (Modified from: MarinPadilla M; ref. 24). 

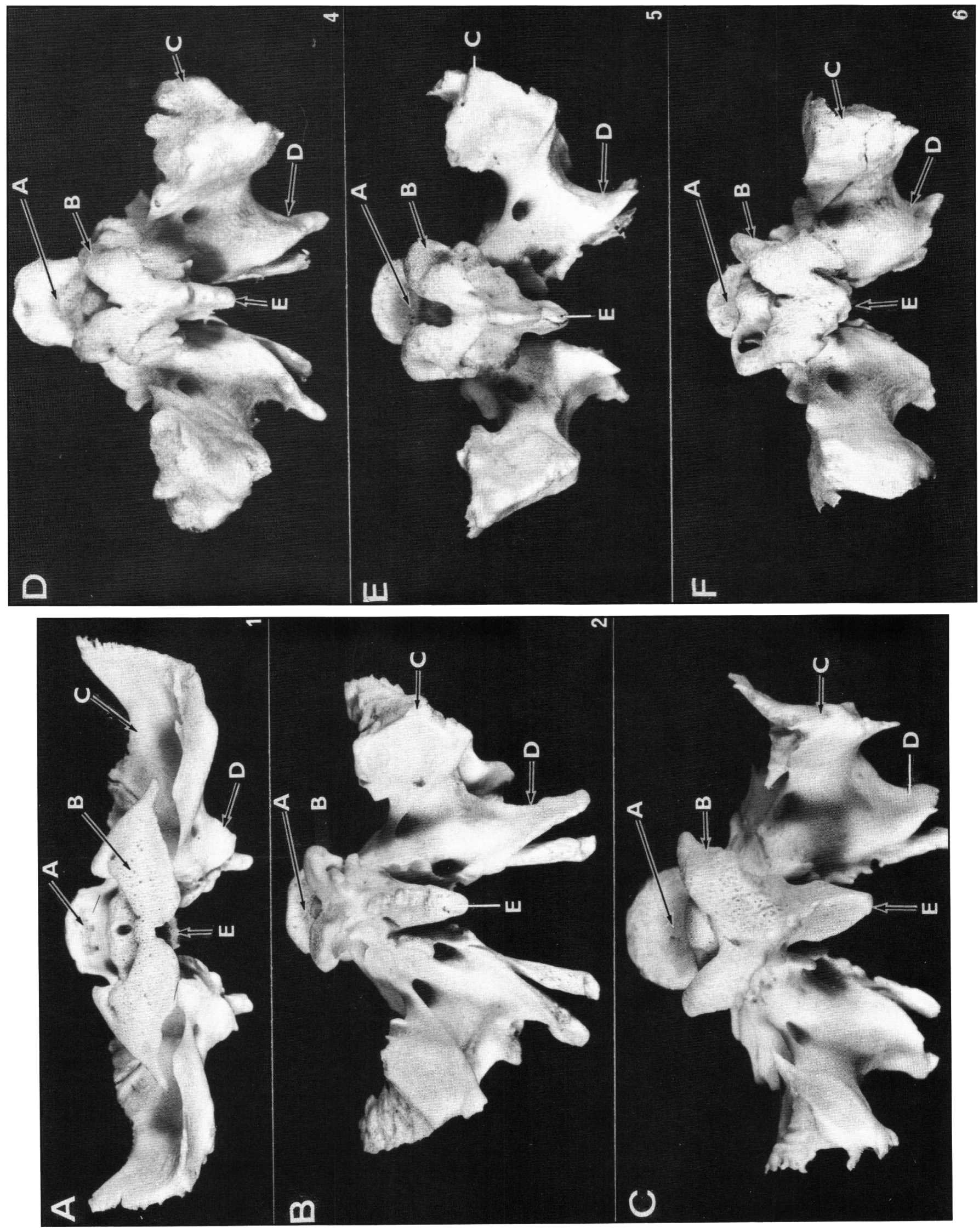

$\underset{0}{\square}$ 
skeletal-neural dysraphic disorders. This last type of cephalic encephalocele will be described here (Table 1). Because of the particular involvement of the subtentorial portion of the axial basicranium, I have selected for this study occipital encephaloceles, which are also the most common variety of this developmental disorder (Figures 5B, C; 6B, and inset). Most studies concerning encephaloceles have emphasized the obvious symptoms causing neural defects and have ignored essential skeletal anomalies. ${ }^{27,36}$ However, to understand this cephalic dysraphic malformation, it is essential to assess its skeletal, neural, and oropharyngeal defects and, subsequently, to evaluate their developmental interrelationships.

All encephaloceles have in common a defect of the neurocranium and a corresponding defect in the dura mater through which the developing nervous tissue becomes extruded. The size of the cranial cavity is often reduced (microcephaly), and the degree of reduction seems to be comparable to the extruded volume of brain. It is possible that in the course of development, the size of the cranial cavity might be able to readjust and compensate for the volume of nervous tissue extruded. In other words, the skeletal changes are secondary to the neurological defects, the persistent assumption found throughout the literature of these malformations. This assumption may be partially correct, but it is not, as indicated below, the whole explanation for the microcephaly in occipital encephaloceles.

Skeletal Defects In CO with occipital encephalocele, the base of the skull is slightly short and lordotic suggesting a primary growth impairment of the axial basicranium (Figure 5B, C). However, it should be emphasized that the sphenoid bone is formed normally in this dysraphic disorder. Consequently, the shortness of the axial basicranium is the result of hypoplasia of the occipital bone. $25-27,36,37$ The hypoplasia or growth impairment affects the whole occipital bone, including the basioccipital, the lateral components, and the planum nuchale (endochondral ossification) of its squama (Figure 5B, C). Because of hypoplasia of the planum nuchale, the posterior attachment of the tentorium is also lower than normal (Figure 5B, C). Consequently, the subtentorial cerebral fossa may be smaller than normal in some of these disorders. The hypoplastic occipital bone and the small subtentorial cerebral fossa certainly contribute to the reduced size of the cranial cavity described in occipital encephaloceles. Therefore, in addition to a possible developmental readjustment to compensate for the extruded volume of CNS, the microcephaly described in some encephaloceles is also the result of a primary hypoplasia of the occipital bone. The small and lordotic subtentorial cerebral fossa of some occipital encephaloceles could also result in the Chiari malformation, occasionally described in severe occipital encephaloceles (Figure 5B black arrow, 5C white arrow).6.14

Neural Defects An encephalocele is a portion of brain tissue extruded through a developmental defect in both the bony neurocranium and the dura mater (paraxial mesodermal origin). The extruded nervous tissue comes in direct contact with the scalp's epidermis without any recognizable dura mater covering or space. However, remnants of leptomeningeal elements and a pial-like vasculature (neural crest origin) may be recognized focally in the surface of the extruded nervous tissue. A direct contact of brain tissue and epidermis without meningeal protective covering is abnormal and, hence, the development of the extruded portion of brain may be secondarily impaired. Hence, some of the neuropathologic alterations found in encephaloceles could represent secondary rather than primary developmental anomalies. A paraxial mesodermal insufficiency affecting the formation the occipital bone, neurocranium, and dura mater (neural folds components) may be the primary anomaly in some types of cephalic encephaloceles. As mentioned above, severe occipital encephaloceles amy be associated with Chiari and/or Dandy-Walker malformations (Figure 5B, C). ${ }^{6,14}$

Oropharyngeal Defects In severe occipital encephaloceles, the shortness of the subtentorial (occipital) basicranium and its lordotic position cause secondary deformations in the oropharyngeal region (Figure $6 \mathrm{~B}, \mathrm{C}$ ). The buccal and pharyngeal cavities are shorter and smaller than normal, and the tongue protrudes slightly anteriorly (Figure 5B, C). The shortness of the base of the skull also causes posterior rotation and slight elevation of the larynx (Figure 5B, C, black/white arrows). By the time of birth, the level of the epiglottis should be at about the level of the second vertebra below the atlas, and its position should be nearly vertical (Figure 5E). ${ }^{43}$ In $\mathrm{CO}$ with occipital encephalocele, the epiglottis is compressed, oblique, rotated posteriorly and slightly elevated (Figure 5B, C). The epiglottis may be level with the odontoid process but above the atlas (Figure 5B, C, black/white arrows). The anomalous position and

Figure 5 - For comparative purposes and to illustrate their basic developmental malformations, midsagittal head sections from: $(\boldsymbol{A})$ premature infant with Chiari malformation and secondary hydrocephalus; $(\boldsymbol{B})$ premature infant with cranioschisis occulta and a large occipital encephalocele; $(C)$ glass-slide montage of a section of the same case for its microscopic study: $(\boldsymbol{D})$ premature infant with cranioschisis aperta, occipital schisis and cervical rachischisis, and, (E) schematic ink-drawing of a normal newborn's head are reproduced. The shortness and lordosis of the basicranium, the shortness and funnel shaped posterior cerebral fossa, the compression and displacement of the aqueduct, hindbrain, cerebellum and medulla, the shortness of the buccal and pharyngeal cavities and the tongue protruding beyond the incisor teeth, and the anomalous position and elevation of the larynx that characterize these dysrapic disorders are clearly illustrated $(\boldsymbol{A}, \boldsymbol{B}, \boldsymbol{C})$. The black/white arrows $(\boldsymbol{A}$, $\boldsymbol{B}, \boldsymbol{C}, \boldsymbol{D})$ indicate the level of the epiglotis in relation to the base of the skull, and the black arrows $(\boldsymbol{A}, \boldsymbol{B})$ a bend in the medulla caused by the downward displacement of the subtentorial CNS elements. Notice in the Chiari malformation (A) and in the occipital encephalocele $(B, C)$ the shortness of the basi-occipital, the lordotic angulation of the base of the skull, and the small posterior cerebral fossa ( $\boldsymbol{A}$ white arrows), which is further complicated by the hydrocephalus' lowering of the tentorium $(A)$. The involvement of the cervical axial skeleton (cervical spina bifida), the extreme shortness of the axial basicranium, and the relatively large facial skeleron are clearly demonstrated in the skull $(\boldsymbol{D})$ of cranioschisis aperta, occipital schisis and cervical rachischisis. For comparative purposes, a schematic reproduction of a normal newborn's head $(\boldsymbol{E})$ is included to illustrate some of its basic parameters including: the angle of the skull base versus the vertebral column, the cerebral cavity size (CC), the location of the tentorium (TE) and its attachment to the occipital spine $(D)$ at or above the level of the sella turcica, the size and shape of the posterior fossa $(P F)$, the relationships of the nasal $(P)$, buccal $(M)$, pharyngeal $(P, P H)$, and laryngeal cavities (large arrow) to the base of the skull, the location of the tongue $(T)$ behind the incisor teeth (small arrows), and the overall size and shape of the newborn's head (NB). Key: $h=$ hydrocephalus, $s=$ sphenoid, $o$ = basi-occipital and squama occipitalis, $m=$ medulla, $c=$ cerebel lum, and $w g=$ week of gestation. The cervical vertebrae are numbered. 


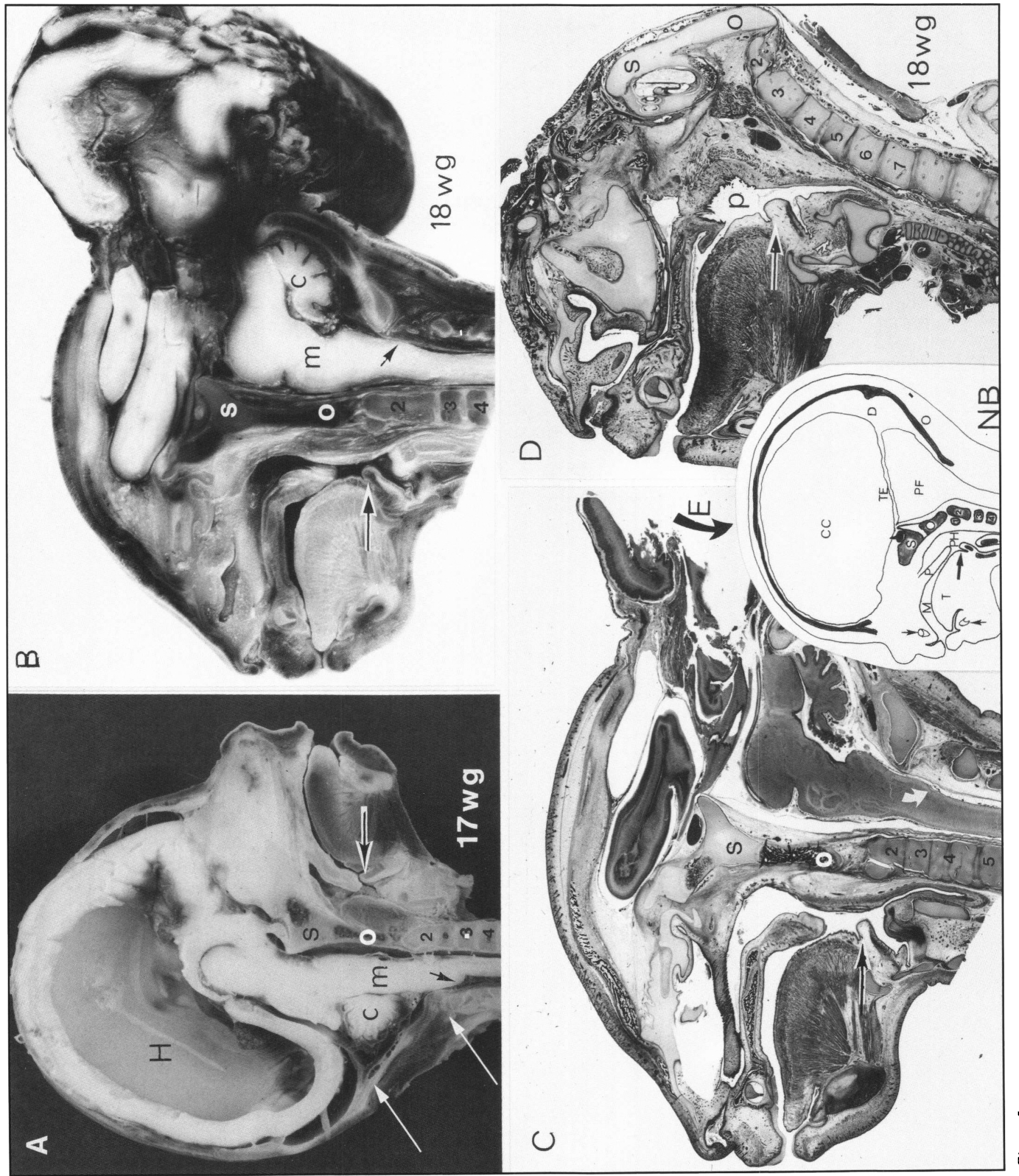

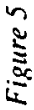


slight elevation of the larynx is these infants should be carefully evaluated if endotracheal intubation may be required for the encephalocele's surgical correction.

Some types of $\mathrm{CO}$ with occipital encephalocele represent axial skeletal-neural dysraphic disorders and, hence, they are developmentally related to CA (anencephaly) and the CM. This type of $\mathrm{CO}$ with occipital encephalocele is believed to be caused by moderate paraxial mesodermal insufficiency that impairs the formation of the occipital bone and the elevation of the cephalic neural folds, causing a defect $\mathrm{n}$ the neurocranium and dura mater through which a portion of the developing brain extrudes.

\section{The Chiari Malformation}

The Chiari malformation (CM) also represents a special type of axial skeletal-neural dysraphic disorder characterized by distinct skeletal, neural, and oropharyngeal defects. ${ }^{26,44-56}$ It shares with $\mathrm{CA}$ and $\mathrm{CO}$ a similar type of involvement of the axial basicranium and differs from them in the degree of involvement of the neural folds (neurocranium) and, consequently, the CNS (Table 1). The different neurological defects that characterize $\mathrm{CA}, \mathrm{CO}$, and the $\mathrm{CM}$ reflect the degree of impairment in the closure of the neural folds, while their skeletal defects reflect a common type of injury affecting the development of the axial basicranium. The oropharyngeal defects that characterize all of these malformations reflect secondary deformations or adaptation to an abnormally short base of the skull (Figure 5, compare A, B, C, D and E).

Skeletal Defects In the CM, the base of the skull is shorter than normal and slightly lordotic (Figure 5A). However, only the subtentorial portion of the axial basicranium is smaller than normal. Its anterior or supratentorial component is not affected and, hence, the sphenoid bone is essentially normal in the CM. The shortness of the subtentorial portion of the basicranium is caused by primary hypoplasia of the occipital bone (Figure 5A). 6,7.9.14 The hypoplasia of the whole occipital bone results in a small subtentorial cerebral fossa (Figure $5 \mathrm{~A}$ ). Consequently, the otherwise normal embryonic growth of the hindbrain and cerebellum become eventually compromised by lack of an adequate space.

Neural Defects A variety of neurological anomalies affecting the subtentorial CNS and its meninges have been described in the CM. ${ }^{46.48-56}$ They have been mainly interpreted as primary neurological anomalies, including: downward traction, downward displacement, overgrowth, maldevelopment, and increased intracranial pressure upon the tentorium by hydrocephalus. A variety of hypotheses have been proposed, including hydrodynamic disturbances of cerebro-spinal fluid, mechanical traction by the myeloschisis, focal overgrowth, and dysgenesis of the subtentorial CNS. None of these hypotheses includes any reference to the axial skeletal and oropharyngeal defects that also characterize the CM. ${ }^{26}$ However, recent studies have demonstrated posterior fossa anomalies compatible with occipital bone hypoplasia even in the adult forms of the Chiari malformation. ${ }^{45.47}$ As emphasized elsewhere, all the neurological anomalies that characterize this clinical entity can be explained by a primarily small posterior fossa that eventually becomes inadequate to accommodate the growing subtentorial components of the CNS. Consequently, the cerebellum, the hindbrain, and the aqueduct of Sylvius become cramped and deformed within the small posterior cerebral fossa. Eventually, they are forced to continue their growth downward because the tentorium acts as a barrier for upward displacement, and the foramen magnum is the only possible outlet for the growing nervous tissue. Therefore, in the CM there are neither primary displacement or herniation of nervous tissue, but simply an overflow from the small space available and a forced outgrowth of the nervous tissue through the foramen magnum. Furthermore, the aqueduct compression, rather than stenosis, that results from crowding causes a progressive hydrocephalus that increases the pressure upon the tentorium, worsening the already cramped conditions within the posterior fossa. Consequently, a posterior fossa decompression, as early as possible, is the only possible solution to the problem and, indeed, the only way of avoiding the devastating neurological sequelae of this developmental disorder. $18,19,16$

Oropharyngeal Defects Children with CM frequently have a small buccal cavity and an apparently large tongue that protrudes slightly and that seems to fill the entire mouth (Figure 5A). The pharyngeal cavity is also small and short, and the soft palate may appear to be large and compressed. The larynx may be slightly elevated and posteriorly rotated. The level of the epiglottis might also be elevated and above the odontoid process of the second vertebra (Figure 5A, black/white arrow). These oropharyngeal defects are secondary deformations resulting from adaptation of facial skeleton to a primarily short and lordotic axial basicranium (Figure 5A). Recognizing these oropharyngeal defects should be crucial to neurosurgeons and anesthesiologists using an anterior approach for the posterior fossa decompression in the treatment of the $\mathrm{CM}$ and endotracheal intubation.

Figure 6-Composite figure illustrating several types of vitamin A induced axial skeletal-neural dysraphic malformations in the golden hamster, including $(B, C)$ cranioschisis occulta $(C O)$ with encephalocele; $(D, F)$ Chiari malformation $(C M)$ with compression, deformation and displacement of the subtentorial CNS; and, $(\boldsymbol{G}, \boldsymbol{H})$ cranioschisis aperta $(C A)$ with encephaloschisis/exencephaly. For comparative purposes, midsagittal sections of normal hamister fetuses $(A, E)$ are included to illustrate some of the normal parameters of their skeletal-neural axis. In addition, ink-drawings reconstructions of the entire axial skeleton of a normal hamster fetus (normal) and of a fetus with cranioschisis occulta $(C)$, encephalocele and lumbosacral rachischisis $(R)$ are included for comparative purposes and to highlight the shortness and lordosis of the axial basicranium, the lumbo-sacral vertebral anomalies (spina bifida), the overall shortness of the affected vertebral axial sketeton, and the fussed spinal ganglia $(\boldsymbol{F} \cdot G)$ of the treated hamster. The fetuses' age ranges from 14 to 15 day's of gestation. All the developmental anomalies that characterize axial skeletal-neural dysraphic disorders are recog. nized in vitamin A treated animals, including: shortness and lordosis of the skull base in all cases; small and fumnel shaped posterior cerebral fossa $(\boldsymbol{D})$; encephaloschisis/exencephaly $(\boldsymbol{G}, \boldsymbol{H})$, encephalocele $(\boldsymbol{B}, \boldsymbol{C})$, or the Chiari malformation $(\boldsymbol{D}, \boldsymbol{F})$ with compression and deformation of aqueduct of Sylvius, hindbrain and cerebellum (compare $\boldsymbol{E}$ and $\boldsymbol{F}$ ), or lumbo-sacral rachischisis with myeloschisis or meningomyelocele (compare ink-drawings of the axial skeletons); shortness and narrowness of buccal and pharyngeal cavities with the tongue protruding beyond the incisor teeth (black and white arrow's) in all cases; and, compression of pharynx. elevation of larynx and cephalic lordosis in all cases. 


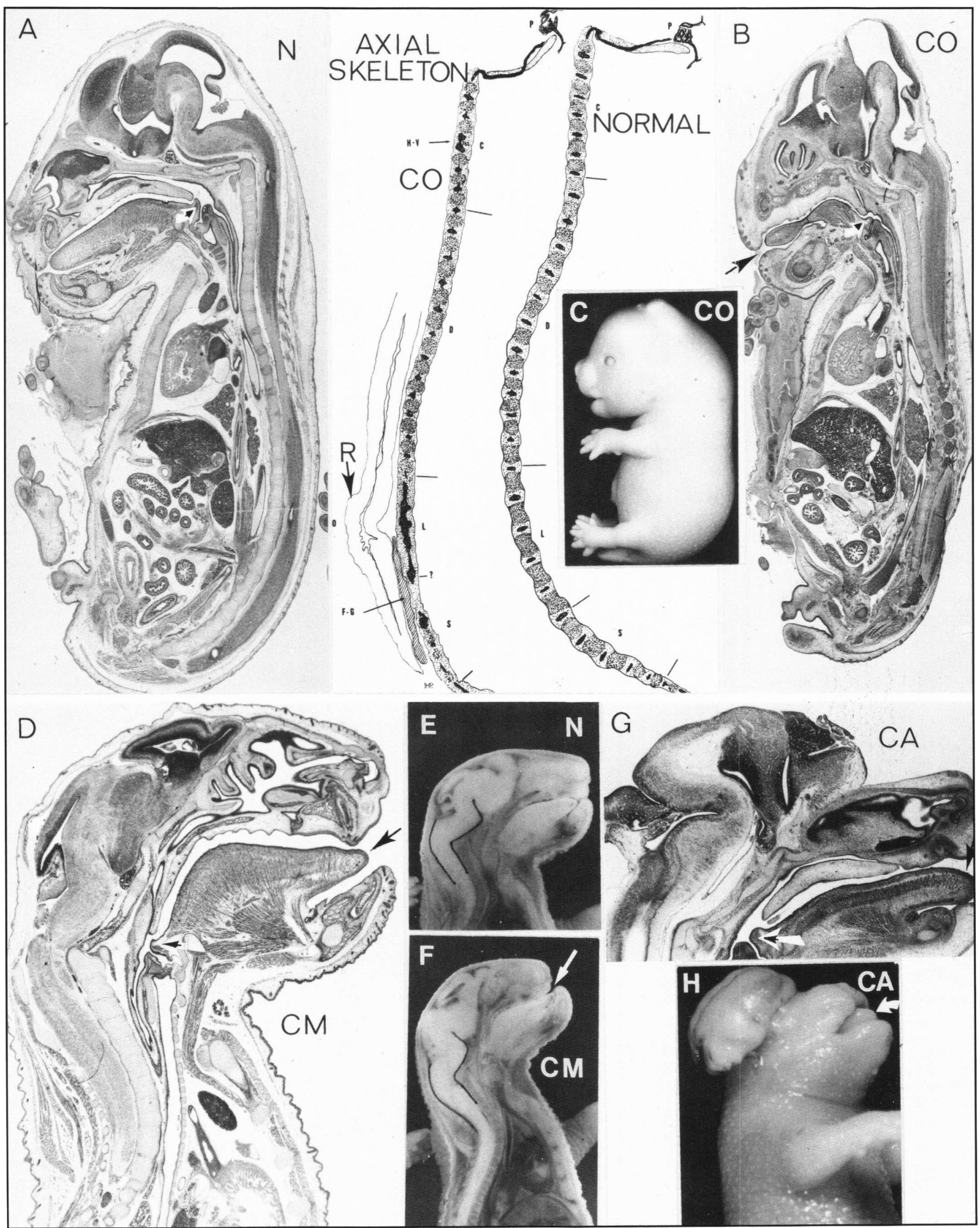


Table 1. Classification of cephalic axial skeletal-neural dysraphic disorders according to the proposed concept of an original paraxial mesodermal insufficiency affecting, primarily, the formation of axial basicranium (skeletal defects) and the elevation of the neural folds interfering with their closure (Neural defects) and, secondarily, the topography of the facial skeleton (oropharyngeal defects).

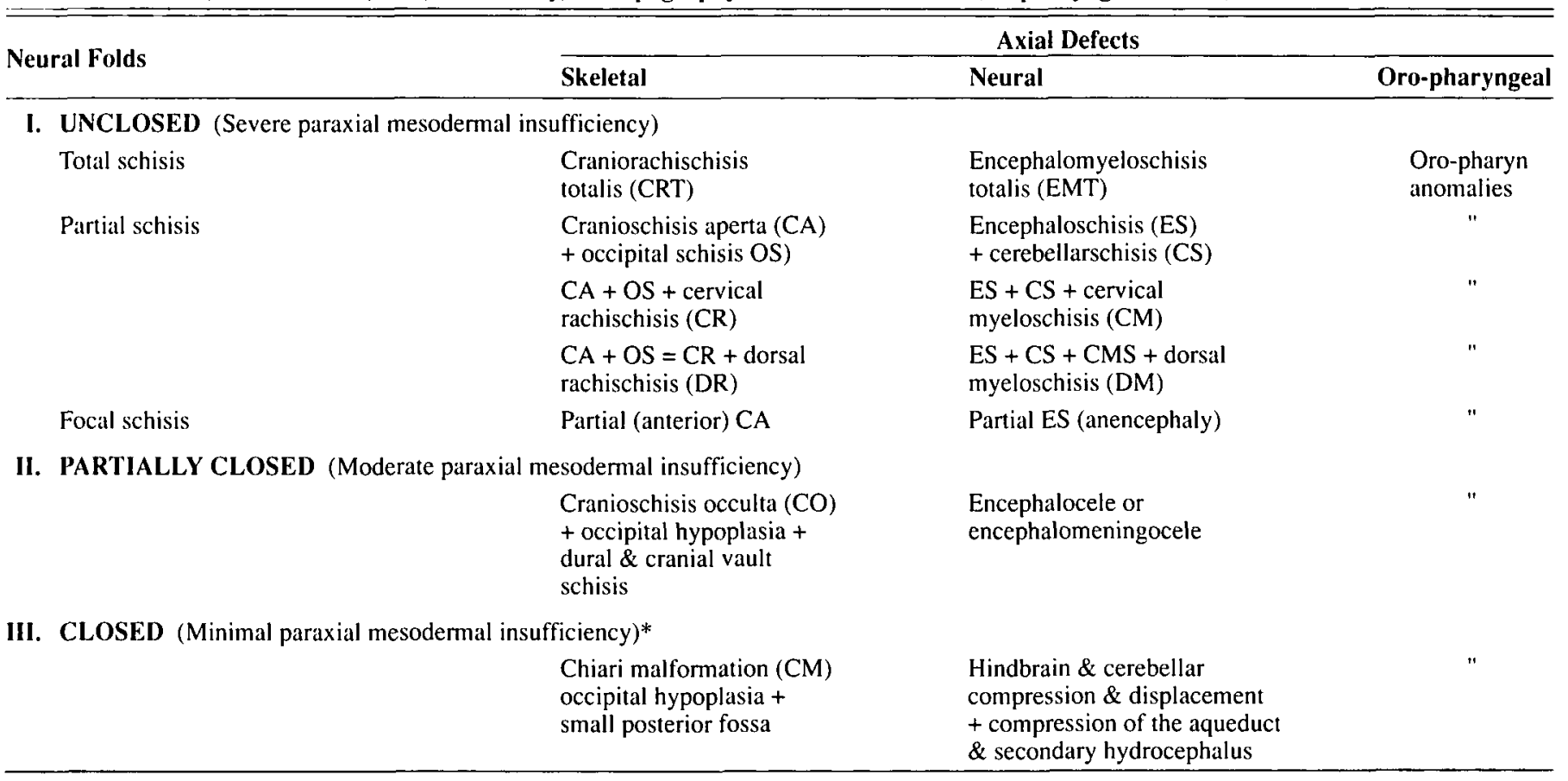

* Possibly Klippel-Feil and Dandy-Walker malformations belong to this group of axial skeletal-neural dysraphic disorders. ${ }^{14.26 .50 .57 .58}$

\section{Experimental Axial Skeletal-Neural DYSRAPHIC DISORDERS}

All the clinical types of axial skeletal-neural dysraphic disorders can be experimentally reproduced with a variety of teratogens, $3,5,10,12,13,23-27,33-37,53$ The oral administration of a single dose of vitamin A to pregnant hamsters at the primitive streak and early somitic embryonic stages can result in: CA with encephaloschisis (exencephaly), $\mathrm{CO}$ with encephalocele, CM with compression and distortion of subtentorial CNS structures, as well as, caudal rachischisis with myeloschisis or meningomyelocele. Illustrated in Figure 6 are examples of vitamin $A$ induced dysraphic disorders (B, C, D, F, G, H), of control animals $(A, E)$ and the reconstructions of the entire axial skeleton of a normal fetus and of a vitamin A treated one with $\mathrm{CO}$, encephalocele and caudal rachischisis with meningomyelocele. Midsagittal sections of treated and control fetuses have been selected to illustrate the fundamental defects that characterize these malformations (Figure 6). The length and position of the axial basicranium; the size and orientation of the facial skeleton and related nasal, buccal, pharyngeal, and laryngeal regions; the size, shape and angulation of the posterior cerebral fossa; and, the condition of the subtentorial CNS structures of normal and treated fetuses can be comparatively evaluated in these sections (Figure 6D, E, F).

First of all it should be emphasized that vitamin $\mathrm{A}$ induced dysraphic disorders, like the clinical malformations, are also characterized by axial skeletal, neural, and oropharyngeal defects (Figure 6). In experimental CA with encephaloschisis and exencephaly, the facial skeleton is proportionally larger than the cranium, the head is elevated, the maxilla is short, the buccal cavity is small, and the tongue protrudes beyond the incisive teeth (Figure $6 \mathrm{H}$ ). The axial basicranium is extremely short and lordotic and lacks a suitable cavity to lodge the brain, which becomes extruded (exencephaly). By the time of birth the brain shows signs of early degeneration (Figure 6G). The pharynx is short, and the larynx is elevated (Figure 6G). The epiglottis in these treated fetuses is at about the level of the basioccipital, while it should normally be at about the level of the third vertebra (Figure 6A, G).

In experimental $\mathrm{CO}$ with encephalocele, the axial basicranium, particularly its posterior portion, is also short and lordotic, the buccal cavity is short so that the tongue protrudes beyond the incisive teeth, the pharynx is short and compressed, and the larynx is compressed and it may be elevated. The developing brain extrudes through a defect in the neurocranium and dura mater and comes in direct contact with the epidermis (Figure 6B, C). The electron-microscopic study of the herniated encephalocele has demonstrated that the nervous tissue is in contact with the epidermis, that the neuroectoderm (neural tube proper) is incompletely closed with large fenestrations through which neuronal and glial processes escape into the ventricle and out into the epidermal tissue. 27

In experimental $\mathrm{CM}$, the posterior (occipital) axial basicranium is short and lordotic, the tongue also protrudes, the maxilla is slightly backward in position, the pharynx is short and compressed, and the larynx is elevated (Figure 6D, F). The subtentorial cerebral fossa is funnel-shaped and small. The hindbrain and the cerebellum are compressed, deformed, and displaced downward, and the medulla is bent (Figure 6D, F). Both the aqueduct of Sylvius and the IV ventricle are extremely compressed (Figure 6D, F). 
In conclusion, it can be stated that: a) both clinical and experimental (vitamin A induced) cephalic axial skeletal-neural dysraphic disorders are essentially similar kinds of developmental malformations characterized by identical skeletal, neural, and oropharyngeal defects and $b$ ) that these are not primary neurological disorders, as has been proposed, but complex developmental malformations that alter the formation of the axial basicranium (skeletal defects), the elevation and closure of the neural folds (neural defects) and, secondarily, the topography of the viscerocranium (oropharyngeal defects).

\section{EMBRYogenesis AXIal Skeletal-NeUral DYSRAPHIC DISORDERS}

A description of the skeletal, neural, and oropharyngeal pathologic defects that characterize clinical and experiment axial skeletal-neural dysraphic disorders has been presented. The study of three basic types of cephalic malformations has been considered adequate to establish their developmental nature and interrelationships. They include: cranioschisis aperta with encephaloschisis (anencephaly and/or exencephaly), cranioschisis occulta with occipital encephalocele, and the Chiari malformation (occipital bone hypoplasia) with hindbrain, cerebellar, and medulla compression, deformation, and displacement. This study emphasizes that these are not simple neurological disorders but complex developmental malformations in which, in addition to the CNS involvement, the axial basicranium, neurocranium, and viscerocranium are also affected.

To understand these complex malformations it is necessary to reevaluate and, eventually, to resolve various aspects of their origin and embryonic development. A common denominator must be established to explain the developmental interrelationships among all the different types of malformations that constitute this heterogeneous group of clinically associated dysraphic disorders. That common denominator must also be capable of explaining the developmental interrelationships among the skeletal, neural, and oropharyngeal defects for each type of malformation. It is also essential to establish and to distinguish, for each basic malformation, primary developmental defects from secondary ones, as well as from anomalies of position and/or deformation. An appropriate terminology should be established that reflects their developmental nature, their embryologic interrelationships, and their distinctive skeletal, neural, and oropharyngeal pathologic defects. The nomenclature proposed here responds to those requirements (Table 1). In addition, it must be clearly understood that the axial skeletal-neural disorders (clinical or experimental) presented and described in this communication represent a specific type of dysraphic malformation but not necessarily the only possible one. The distinctive and developmentally interrelated axial skeletal, neural, and oropharyngeal defects distinguish this particular and heterogeneous group of dysraphic malformations.

The Hensen node and primitive streak complex is the most active area of the young embryo, and the source of paraxial mesodermal cells among other early embryonic components (notochord, neural plate, surface ectoderm, endoderm). The embryo actually emerges progressively from this active zone. Paraxial mesodermal cells fill the embryo, elevate the neural folds, and concentrate to establish the axial chordamesoderm, and to form tandem somitomeres earlier and somites later and a pair of cephalic parachordal plates from which the anterior portion of the axial basicranium evolves.

These paraxial mesodermal roles progress sequentially and segmentally in a cephalo-caudal gradient in the formation of the mammalian embryo skeletal-neural axis. In human embryos, the cephalic region is first established (ca. 18 days-old) and is progressively and segmentally succeeded by the formation of the following regions: the occipital (ca. $20 \mathrm{~d}$-o), the cervical (ca. 22 d-o), the thoracic (ca. $25 \mathrm{~d}-0$ ), the lumbar (ca. $27 \mathrm{~d}-0$ ), the sacral (ca. $28 \mathrm{~d}$-o), and the coccigeal (ca. $30 \mathrm{~d}$-o). Although these embryonic ages represent mere approximations, they are of great significance for the timing of the various types of malformation, and are needed to explain the malformations' developmental heterogeneity. For instance, an injury occurring around the twenty-sixth day of gestation does not result in cranioschisis aperta with encephaloschisis but could result in lumbar rachischisis with myeloschisis and/or meningomyelocele.

An injury to the Hensen node/primitive streak complex that reduces the number of paraxial mesodermal cells could impair the formation of the skeletal-neural axis of the embryo without stopping it altogether. Such an injury has to be mild because a severe one could actually hinder the formation of the whole embryo. A simple reduction in the number of available paraxial mesodermal cells (occurring at specific embryonic ages) is proposed herein as the fundamental and common developmental defect for this of group of dysraphic malformations. It should also be emphasized that the actual development of the skeletalneural axis components progresses normally (although impaired) in these malformations. Consequently, although some of them might be growth-impaired they are nonetheless developed and formed at their normal times.

A reduction of paraxial mesodermal cells could simply impair (locally or totally) the formation of the axial skeleton causing skeletal defects as well as the degree of elevation of the neural folds thus interfering (partially or totally) with their closure and causing neural defects. The oropharyngeal defects represent secondary anomalies of adaptation and/or deformations to the abnormal basicranium. The reduction (insufficiency) of available paraxial mesodermal cells may be severe, moderate, or minimal and the resulting malformation should reflect that fact (Table 1). In addition, the timing, as well as the duration, of the mesodermal insufficiency plays a significant role in the final type of malformation. An early, brief paraxial mesodermal insufficiency only impairs the formation of the anterior axial basicranium (causing partial cranioschisis aperta) and the closure of the anterior cephalic neural folds (causing encephaloschisis). A similar degree of insufficiency but of a longer duration additionally and sequentially impairs the formation of lower segmental regions of the skeletal-neural axis resulting in craniochisis aperta with occipital schisis, as well as in malformations with lower dysraphias (Table 1). As severe and prolonged mesodermal insufficiency can actually impair the formation of the entire skeletal-neural axis, causing craniorachischisis and encephalomyeloschisis totallis (Table 1). Intermediate types of malformations result from variations in the time of the insufficiency and its duration. Furthermore, a mesodermal insufficiency can occur during the formation of the skeletal-neural axis of the caudal region and can result in different types of lumbo-sacral 
rachischisis (skeletal defect) and myeoschisis and/or meningomyelocele (neural defect). Cephalic as well as Caudal defects are essential components of this heterogeneous group of dysraphic malformations which are known to be familiarly and clinically associated. 8,13

A better understanding of the origin and developmental nature of these axial skeletal-neural dysraphic disorders should improve their clinical management, the exploration of corrective surgical approaches, and the future outlook for the unfortunate infants born with these devastating malformations. This understanding should also facilitate the exploration of possible preventive measures.

\section{ADDENDUM}

The excellent work of Fabiola Müller and Ronan O'Rahilly on the early embryonic stages of anencephaly (Development of Anencephaly and its Variants. Am. J. Anat. 190: 193-218, 1991) has come to my attention after the submission of my contribution. Their descriptions of the chondrocranium in these malformations are elegant and unique. Their conclusions corroborate many of my views about the nature of these axial dysraphic disorders. They too believe that the axial skeletal defects are probably primary anomalies (early paraxial mesenchyme disturbance), while the central nervous system involvement is more likely to represent secondary defects. They also pointed out that there are no appreciable primary neural crest disturbances in these malformations.

\section{ACKNOWLEDGEMENT}

This work has been supported by a Jacob Javits Neuroscientist Investigator Award from the National Institute of Neurological Disorders and Stroke, Grant \# NS-22897, NIH, USA.

\section{REFERENCES}

1. Recklinhausen FV. Untersuchungen über die Spina Bifida. II Ueber die Art und die Entstehung der Spina Bifida, ihre Beziegung zür Rücknmarks und Darmspalte. Virchows Arch Path Anat 1896; 105: 296-330.

2. Morgagni JG. De Sedibus et Causis Morborum per Anatomen Indagacione. Veneti 1761. The Seats and Causes of Diseases Investigated by Anatomy: Engish translation, Alexander B, London, Millar \& Capell, 1869.

3. Lemire RJ, Beckwith JB, Walkany J. Anencephaly. New York: Raven Press 1978; 11-133.

4. Elwood JM, Elwood JH. Epidemiology of Anencephalus and Spina Bifida. New York: Oxford Univ Press 1980; 1-27.

5. Walkany J. Congenital Malformations: Notes and Comments. Chicago: Year Book Publisher 1971; 189-296

6. Larroche JC. Malformations of the nervous system. In: Greenfields Neuropathology. Adams JH, Corsellis JAN, Duchen LW, eds. New York: John Wiley \& Sons 1984; 385-45I.

7. Friede RL. Developmental Neurpathology. Berlin: Springer Verlag 1989; 247-291.

8. Marín-Padilla M. Morphogenesis of anencephaly and related malformations. Current Topics in Pathology 1970; 51: 145-174.

9. Gardner WJ. The Dysraphic States. From Syringomyelia to Anencephaly. Amsterdam: Exceprta Medica 1973; 1-56.

10. Giroud A. Anencephaly. In: Handbook of Clinical Neurology, vol 30. Vinken PS, Bruyn GW, eds. Amsterdam: Elsevier/North Holland 1977; 173-208.

11. Dadmanabhan R. Light microscopic study on the pathogenesis of exencephaly and cranioschisis induced in rat after neural tube closure. Teratology 1988; 37: 29-36.
12. Peters PWJ. Induced congenital malformations of the central nervous system. A teratological study monograph. Lisse: Swetts \& Zeitlinger 1981; 5-73.

13. Marín-Padilla M. Clinical and experimental rachischisis. In: Handbook of Clinical Neurology, vol 32. Contgenital Malformations of the Spine and Spinal Cord. Vinken PJ, Bruyn GW, eds. Amsterdam: Elservier/North Holland 1978; 159.191.

14. McLaurin RL. Encephalocele and cranium bifidum. In: Handbook of Clinical Neurology, vol 50, Malformations. Myrianthopolous N, ed. Amsterdam: Elsevier Publishers 1987; 97-111.

15. Welch K, Winston KR. Spina Bifida. In: Handbook of Clinical Neurology, vol 50, Malformations, Myrianthopolous N, ed. Amsterdam: Elseview Publishers 1987; 477-508.

16. Bamberger-Bozo C. The Chiari II malformation. In: Handbook of Clinical Neurology, vol 50. Malformations. Myrianthopolous, ed. Amsterdam: Elsevier Publishers 1987; 403-412.

17. Padget D. Neuroschisis and human embryonic development. New evidence on anencephaly, spina bifida and diverse mammalian defects. J Neuropath Exp Neurol 1970; 29: 192-216.

18. Meneses AH, VanGilder JC. Transoral-transpharyngeal approach to the anterior craniocervical junction. 10 year experience of 72 patients. J Neurosurg 1988; 69: 895-903.

19. Meneses AH, Smoker WRK, Dyste GN. Syringomyelia, Chiari Malformation and Hydromyelia. In: Neurological Surgery, vol 2, third edition. Youmans J, ed. Philadelphia: WB Saunders Company 1990; 1421-1459.

20. Hamilton WJ, Boyd JD, Mossman HM. Human Embryology. Baltimore: William \& Wilkins Publishers 1972; 162-182, 437-525.

21. Marín-Padilla M. Study of the skull in human cranioschisis. Acta Anat 1965; 62: 1-20.

22. de Beer GR. The Development of the Vertebrate Skull. Oxford: Claredon Press 1937; 484-496.

23. Marín-Padilla M. Study of the vertebral column in human craniorachischisis. The significance of the notochordal alterations. Acta Anat 1966; 63: 32-48.

24. Marín-Padilla M. Study of the sphenoid bone in human cranioschisis and craniorachischisis. Virchows Arch Path Anat 1965; 339 . 245-253.

25. Marín-Padilla M. Notochordal-basichondrocranium relationships. Abnormalities in experimental axial skeletal (dysraphic) disorders. J Embryol exp Morph 1979; 53: 15-38.

26. Marín-Padilla M. Morphogenesis of experimentally induced Arnold-Chiari malformation. J Neurol Sci 1981; 50: 29-55.

27. Marín-Padilla M. Morphogenesis of experimental encephalocele (cranioschisis occulta). J Neurol Sci 1980; 46: 83-99.

28. Meier S, Tam PPL. Metameric pattern development in the embryonic axis of the mouse. I Differentiation of the cranial segments. Differentiation 1982; 21: 95-108.

29. Tam PPL. A study on the pattern of prospective somites in the presomitic mesoderm of the mouse embryo. J Embryol Exp Morph 1986; 92: 269-285.

30. Noden DM. Craniofacial development: New views on old problems. Anat Rec 1984; 208: 1-13.

31. Marín-Padilla M, Marín-Padilla TM. Developmental abnormalities of the occipital bone in human chondrodystrophies (Achondroplasia and thanatophoric dwarfism). The National FoundationMarch of Dimes. Birth Defects Series 1977; 13: 7-23.

32. O'Rahilly R, Müller F. The meninges in human development. J Neuropath Exp Neurol 1986; 45: 588-608.

33. Marín-Padilla M. The closure of the neural tube. Teratology 1970; 3: 39-46.

34. Marín-Padilla M. Mesodermal alterations induced by hypervitaminosis A. J Embryol Exp Biol 1966; 15: 261-269.

35. Marín-Padillas $M$. Mesodermal alterations induced with (DMSO) dimethylsulfoxide. Proc Soc Exp Biol 1966; 122: 717-720.

36. Carpenter, S. Developmental analysis of cephalic axial dysraphic disorders in arsenic-treated hamster embryos. Anat Embryol $1987 ; 176: 345-365$.

37. Willhite CC. Arsenic-induced axial skeletal (dysraphic) disorders. Exp Molec Path 1981; 34: 145-158.

38. Keen JA. The morphology of the skull in human anencephalic monsters. S Afr Med J 1962; 8: 1-9. 
39. Fields HW, Metzner L, Garol JD, et al. The craniofacial skeleton in anencephalic human fetuses. I Cranial floor. Teratology 1978; 17: 57-66.

40. Garol JD, Fields JA, Metzner L, et al. The craniofacial skeleton in anencephalic human fetuses. II Calvarium. Teratology 1978; 17: 67-74.

41. Metzner L, Garol JD, Fields, et al. The craniofacial skeleton in anencephalic human fetuses. III Facial skeleton. Teratology 1978: 17:75-82.

42. Marín-Padilla M. Origin, formation, and prenatal maturation of the human cerebral cortex: An overview. J Craniofac Genet Dev Biol 1990; 10: 137-146.

43. England MA. Color Atlas of Life Before Birth. Normal Fetal Development. Chicago: Year Book Med Publishers 1983; 51-69.

44. Roth M. Cranio-cervical growth collision: Another explanation of the Arnold-Chiari malformation. Neuroradiology 1986; $28: 187$. 194.

45. Schady W, Metcalfe RA, Butler P. The incidence of craniocervical bony anomaly in the adult Chiari malformation. J Neurol Sci 1987; 82: 193-203.

46. McLone DG, Knepper PA. The cause of Chiari II malformation: A unified theory. Pediatr Neurose 1989; 15: 1-12.

47. Vega A, Quintana F, Berciano J. Basichondrocranium anomalies in the adult Chiari type I malformations: A morphometric analysis. J Neurol Sci 1990; 99: 137-145.

48. Chiari $H$. Über Veränderungen des Kleinhirns infolge Hydrocephalie des Grosshirns. Dtsh med Wschr 1891; 17: 1172-1175.

49. Chiari H. Über Veränderungen des Kleinhirns des Pons und Medulle Oblongata infolge von Kongenitaten Hydrocephalie des Grosshirns. Denkschr Akad Wiss Wien 1896; 63: 71-116.
50. Gardner WJ. The Dandy-Walker and Arnold-Chiari malformations. Arch Neurol 1976; 33: 519-528.

51. Peach B. The Arnold-Chiari malformation. Morphogenesis. Arch Neurol 1965; 12: 527-535.

52. Peach B. The Amold-Chiari malformation. Anatomical features in 20 cases. Arch Neurol 1965; 12: 613-621.

53. Margolis G, Kilham L. Experimental virus induced hydrocephalus. Relation to pathogenesis of the Arnold-Chiari malformation. J Neurosurg 1969; 31: 1-9.

54. Master CC. Pathogenesis of the Arnold-Chiari malformation. The significance of hydrocephalus and aqueduct stenosis. J Neuropath Exp Neurol 1978; 37: 56-73.

55. Daniel PM, Strich SS. Some observations on congenital deformities of the central nervous system known as Arnold-Chiari malformation. J Neuropath Exp Neurol 1958; 17: 255-266.

56. Salam MZ, Raymond DA. The Arnold-Chiari Malformation. In: Handbook of Clinical Neurology, vol 32. Congenital Malformations of the Spine and Spinal Cord. Myrianthopolous N, ed. Amsterdam: North Holland Publishers 1987; 99-110.

57. Wilkinson M. The Klippel-Feil Syndrome. In: Handbook of Clinical Neurology, vol 32. Congenital Malformations of the Spine and the Spinal Cord. Myrianthopolous N, ed. Amsterdam: North Holland Publishers 1987; 111-122.

58. Miyamoto C, Ishii H, Hamamoto Y. An autopsy case of the KlippelFeil syndrome. Bull Osaka Med Sch 1971; 17: 11-16. 